\title{
Endovascular treatment of resistant hypertension in a young female with focal fibromuscular dysplasia
}

\author{
Sarah Alam, ${ }^{1}$ Hiya Boro, ${ }^{1}$ Priya Jagia, ${ }^{2}$ Alpesh Goyal (1) ${ }^{1}$
}

${ }^{1}$ Department of Endocrinology and Metabolism, All India Institute of Medical Sciences, New Delhi, Delhi, India ${ }^{2}$ Department of Cardiovascular and Interventional Radiology, All India Institute of Medical Sciences, New Delhi, Delhi, India

\section{Correspondence to} Dr Alpesh Goyal; alpeshgoyal89@gmail.com

Accepted 9 June 2020

Check for updates

(C) BMJ Publishing Group Limited 2020. No commercial re-use. See rights and permissions. Published by BMJ.

To cite: Alam S, Boro $\mathrm{H}$, Jagia $\mathrm{P}_{\text {, et al. BMJ Case }}$ Rep 2020;13:e235481 doi: $10.1136 /$ bcr-2020235481

\section{DESCRIPTION}

A 23-year-old woman presented to our department for evaluation of resistant hypertension. She was diagnosed to have hypertension at the age of 16 years while undergoing evaluation for menstrual abnormalities. Her initial and maximum blood pressure readings were 190/120 $\mathrm{mm} \mathrm{Hg}$ and 210/110 $\mathrm{mm} \mathrm{Hg}$, respectively. Her blood pressure control remained suboptimal (all home and office readings $>150 / 90 \mathrm{~mm} \mathrm{Hg}$ ) despite being on four antihypertensive agents-amlodipine $20 \mathrm{mg}$, prazosin $10 \mathrm{mg}$, clonidine $0.3 \mathrm{mg}$ and hydrochlorothiazide $12.5 \mathrm{mg}$ (daily dose). She did not receive renin-angiotensin-aldosterone system (RAAS)blocking agents due to childbearing concerns. There was no history suggestive of renal involvement, autoimmune disorder, thyrotoxicosis, Cushing syndrome, acromegaly, pheochromocytoma or hypokalemic periodic paralysis. Both her medical history and family history were unremarkable. Clinical examination found a young woman with a height of $159 \mathrm{~cm}$, weight of $50 \mathrm{~kg}$ and body mass index of $19.84 \mathrm{~kg} / \mathrm{m}^{2}$. She had elevated, but comparable blood pressure readings in all the four limbs. There was no renal bruit on auscultation. Serum urea, creatinine, potassium, total calcium, inorganic phosphorous, alkaline phosphatase, thyroxine, thyroid-stimulating hormone, cortisol, adrenocorticotrophic hormone, insulin-like growth factor 1 and parathyroid hormone concentrations were normal. Complete urine examination and 24-hour urine catecholamine measurement were also unremarkable. She did not have any evidence of end-organ damage.

Plasma aldosterone and direct renin concentration (DRC) were measured on an autoanalyser using chemiluminescent immunoassay technology (LIAISON, DiaSorin, USA). Blood sample was collected after an overnight fast and patient remained in upright posture for 2 hours after waking up and, then, seated for $15 \mathrm{~min}$ before blood collection. Normokalaemia was ensured and the test results were interpreted in the light of confounding effect caused by patient's antihypertensive medications. ${ }^{1}$ Plasma aldosterone and DRC concentrations were $26.9 \mathrm{ng} / \mathrm{dL}(\mathrm{N}: 2.2-35.3 \mathrm{ng} /$ $\mathrm{dL})$ and $27.9 \mathrm{mU} / \mathrm{L}(\mathrm{N}: 4.4-46.1 \mathrm{mU} / \mathrm{L})$, respectively. These results excluded the possibility of a low-renin state such as primary aldosteronism. Duplex ultrasonography revealed bilateral normal sized kidneys with increased acceleration time in the right segmental renal artery. CT angiography was performed next, revealing focal stenosis of distal right renal artery and poststenotic aneurysm of the branched right renal artery (figure 1). A diagnosis of focal fibromuscular dysplasia (FMD) with resistant renovascular hypertension (RVH) was, therefore, considered and consent for endovascular intervention obtained from the patient.

Digital subtraction angiography revealed a tight stenosis with a pressure gradient of $130 \mathrm{~mm} \mathrm{Hg}$ across the stenosed segment, thus, confirming the diagnosis (figure 1). Percutaneous transluminal balloon angioplasty was performed and postprocedure, the pressure gradient fell to $5 \mathrm{~mm} \mathrm{Hg}$ (figure 2). She had an uneventful recovery and over the next 24 hours her blood pressure reduced progressively. Antihypertensive medications were rapidly decreased and by the postprocedure day 2 , all medications could be withdrawn. She was discharged on day 4 without antihypertensives. At 15 months of follow-up, she continues to remain normotensive without any medications. A

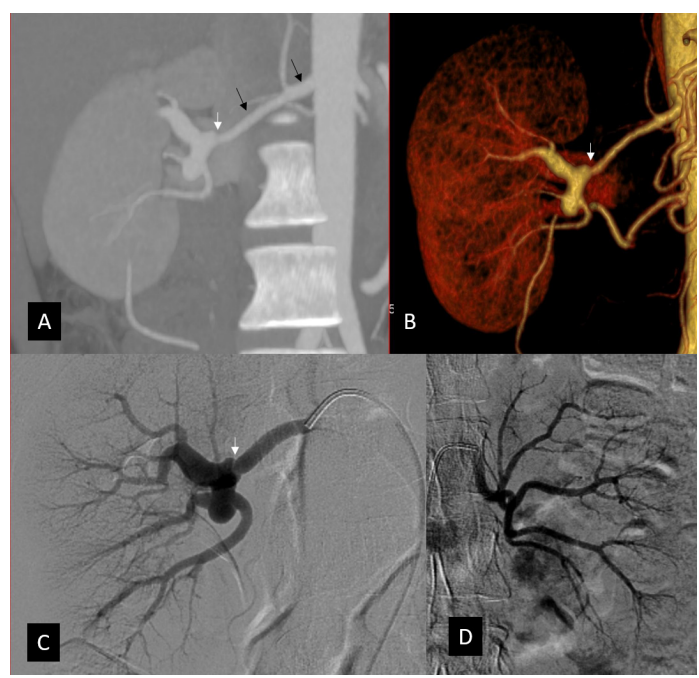

Figure 1 (A) Contrast-enhanced CT angiograph showing normal origin of the right renal artery with normal ostia, proximal and mid-segments (black arrow). In the distal segment, there is a tight stenosis (white arrow) due to web-like constriction followed by poststenotic dilation of branch renal arteries. (B) Virtual reconstructed image shows the same finding (stenotic segment marked by a white arrow). (C) Digital subtraction angiogram showing normal ostia, and proximal and mid-segments of the right renal artery with a web-like structure (white arrow) in the distal segment causing tight stenosis followed by poststenotic dilation of branch renal arteries. (D) Normal digital subtraction angiogram of the left renal artery. 


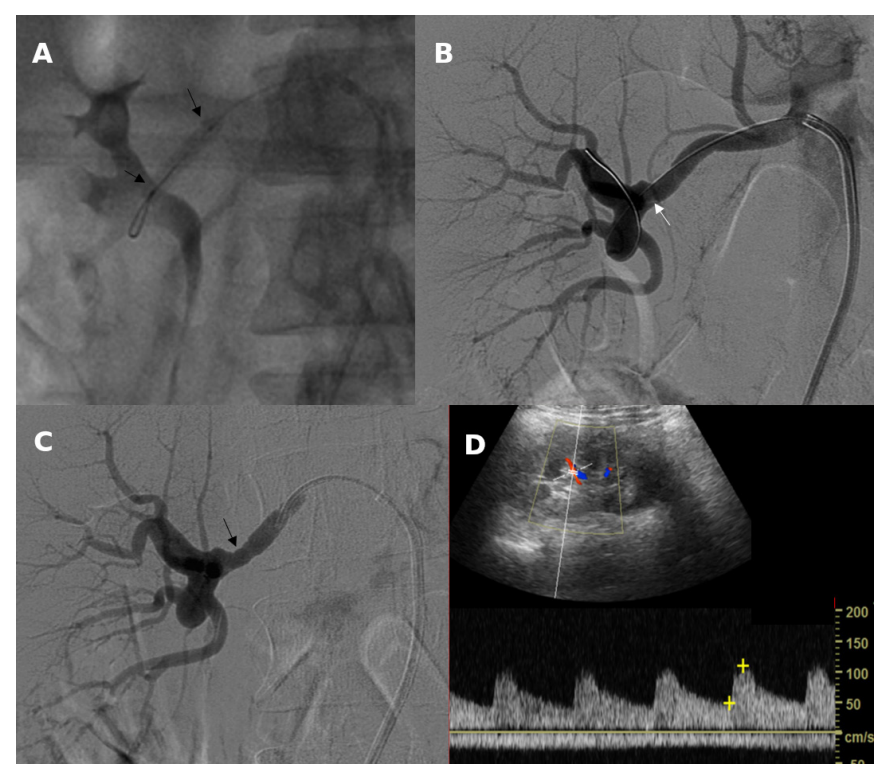

Figure 2 (A) Fluoroscopy image during the right renal angioplasty showing the position of a balloon catheter (black arrow) across the stenotic segment. (B) Digital subtraction angiogram postballoon angioplasty revealing break in the web (white arrow) with brisk antegrade flow without any residual luminal stenosis. (C) Digital subtraction angiogram after removal of the guidewire showing mild spasm (black arrow) in the mid-segment of the right renal artery with brisk antegrade flow in the main renal artery and its branches. Followup duplex ultrasound was done the next day, which showed a normal intrarenal arterial doppler waveform (not shown). (D) A 15-month follow-up duplex ultrasound showing a normal intrarenal arterial Doppler waveform.

follow-up duplex ultrasound performed recently showed normal waveform in the intrarenal arteries (figure 2).

Secondary hypertension is defined as a form of hypertension with an identifiable potentially reversible cause. Overall, it accounts for $5 \%-10 \%$ of all cases of hypertension. The likelihood of finding a secondary cause is often higher in younger subjects with hypertension, with prevalence estimates as high as $30 \%$ in the age group of $18-40$ years. ${ }^{2} \mathrm{RVH}$ is an important cause of secondary hypertension. It accounts for approximately $0.5 \%-$ $4.0 \%$ of all cases in an unselected hypertensive population. ${ }^{3} \mathrm{RVH}$ occurs as a consequence of renal artery stenosis leading to renal ischaemia and RAAS activation. A mere presence of renal artery stenosis in a patient with systemic hypertension should not be labelled as RVH. The diagnosis is actually established in retrospect, when hypertension improves following correction of the culprit lesion. The two major aetiologies of RVH are atherosclerotic renal artery stenosis (ARAS) (85\%-90\%) and FMD (10\%). ${ }^{4}$ FMD is predominantly seen in young women. ARAS has been classically described in elderly men; however, there has been a shift towards female gender in recent years. This is evident from enrolment in the pivotal 'Cardiovascular Outcomes in Renal Atherosclerotic Lesions' study where male-to-female ratio was nearly $1: 1 .^{5}$ While a role of endovascular intervention in the form of angioplasty with or without stenting is well established in FMD, the same is not true for ARAS; there is a lack of conclusive evidence of benefit over the optimal medical treatment. ${ }^{35}$ It is important to recognise RVH as a potential cause of secondary hypertension because timely endovascular intervention in appropriate cases could reverse hypertension and prevent end-organ complications in the long term.

\section{Patient's perspective}

I am extremely pleased with the outcome of my treatment and thank my team of doctors for accomplishing this task. I am happy to share this observation with the entire medical fraternity if it could be of any help.

\section{Learning points}

A secondary cause should always be considered in young patients ( $<40$ years) with hypertension and those with treatment -resistant hypertension.

- Renal artery stenosis is an important cause of secondary hypertension. The two major aetiologies of this condition are atherosclerosis and fibromuscular dysplasia.

- In fibromuscular dysplasia, endovascular intervention in the form of angioplasty with or without stenting is associated with several benefits including improved blood pressure control, reduced antihypertensive requirements and prevention of end-organ complications.

Twitter Hiya Boro @hiya21288

Acknowledgements The authors thank Professor Rajesh Khadgawat and Dr Saurav Khatiwada (Department of Endocrinology and Metabolism) and Dr Manish Shaw (Department of Cardiac Radiology) for their help in managing the patient.

Contributors $\mathrm{SA}, \mathrm{HB}$ and $\mathrm{AG}$ diagnosed and managed the patient, reviewed the literature and drafted the manuscript. PJ performed the endovascular intervention and edited the manuscript. All authors approved the final version of the manuscript.

Funding The authors have not declared a specific grant for this research from any funding agency in the public, commercial or not-for-profit sectors.

Competing interests None declared.

Patient consent for publication Obtained.

Provenance and peer review Not commissioned; externally peer reviewed.

ORCID iD

Alpesh Goyal http://orcid.org/0000-0003-0922-5022

\section{REFERENCES}

1 Funder JW, Carey RM, Mantero F, et al. The management of primary aldosteronism: case detection, diagnosis, and treatment: an endocrine Society clinical practice guideline. J Clin Endocrinol Metab 2016;101:1889-916.

2 Young WF, Calhoun DA, Lenders JWM, et al. Screening for endocrine hypertension: an endocrine Society scientific statement. Endocr Rev 2017;38:103-22.

3 Safian RD, Textor SC. Renal-Artery stenosis. N Engl J Med Overseas Ed 2001;344:431-42.

4 Mehta AN, Fenves A. Current opinions in renovascular hypertension. Proc 2010;23:246-9

5 Cooper CJ, Murphy TP, Cutlip DE, et al. Stenting and medical therapy for atherosclerotic renal-artery stenosis. N Engl J Med 2014;370:13-22 
Copyright 2020 BMJ Publishing Group. All rights reserved. For permission to reuse any of this content visit https://www.bmj.com/company/products-services/rights-and-licensing/permissions/

BMJ Case Report Fellows may re-use this article for personal use and teaching without any further permission.

Become a Fellow of BMJ Case Reports today and you can:

- Submit as many cases as you like

- Enjoy fast sympathetic peer review and rapid publication of accepted articles

- Access all the published articles

Re-use any of the published material for personal use and teaching without further permission

Customer Service

If you have any further queries about your subscription, please contact our customer services team on +44 (0) 2071111105 or via email at support@bmj.com.

Visit casereports.bmj.com for more articles like this and to become a Fellow 